\title{
Infrared spectroscopic study of the synthetic Mg-Ni talc series
}

5

6

7

Marc Blanchard ${ }^{1}$, Merlin Méheut ${ }^{1}$, Louise Delon ${ }^{1}$, Mathilde Poirier ${ }^{1}$, Pierre Micoud $^{1}$,

8

Christophe Le Roux ${ }^{1}$, François Martin ${ }^{1}$

9

10

${ }^{1}$ Géosciences Environnement Toulouse (GET), Université de Toulouse, CNRS, IRD, UPS, 14 avenue Edouard

11 Belin, 31400 Toulouse, France

12

13

14

15

16 Corresponding author: Marc Blanchard

17 E-mail: marc.blanchard@get.omp.eu 
Five talc samples $\left((\mathrm{Mg}, \mathrm{Ni})_{3} \mathrm{Si}_{4} \mathrm{O}_{10}(\mathrm{OH})_{2}\right)$ covering the entire $\mathrm{Mg}-\mathrm{Ni}$ solid solution were synthesized following a recently developed and patented process (Dumas et al. 2013a, b), which produces sub-micron talc particles replying to industrial needs. Near- and midinfrared spectra were collected and compared to infrared spectra modeled from first-principles calculations based on density functional theory. The good agreement between experimental and theoretical spectra allowed assigning unambiguously all absorption bands. We focused in particular on the four main $\mathrm{OH}$ stretching bands, which represent good probes of their local physical and chemical environment. The description of the vibrational modes at the origin of these absorption bands and the theoretical determination of absorption coefficients provide a firm basis for quantifying the talc chemical composition from infrared spectroscopy and for discussing the distribution of divalent cations in the octahedral sheet. Results confirm that these synthetic talc samples have a similar structure as natural talc, with a random distribution of $\mathrm{Mg}$ and $\mathrm{Ni}$ atoms. They only differ from natural talc by their hydrophilic character, which is due to their large proportion of reactive sites on sheet edges due to sub-micronic size of the particles. Therefore the contribution on infrared spectra of hydroxyls adsorbed on edge sites has also been investigated by computing the infrared signature of hydroxyls of surface models.

Keywords: Talc, hydrothermal synthesis, Infrared spectroscopy, first-principles calculation, DFT. 


\section{Introduction}

Talc is a trioctahedral phyllosilicate with the structural formula $\mathrm{Mg}_{3} \mathrm{Si}_{4} \mathrm{O}_{10}(\mathrm{OH})_{2}$. A representation of its structure can be found for instance in Dumas et al. (2015), where we see the octahedral sheet containing $\mathrm{Mg}$ atoms sandwiched by two tetrahedral sheets containing $\mathrm{Si}$ atoms. In talc, each hydroxyl group is bonded to three octahedral cations $(\mathrm{Mg})$ and is oriented perpendicular to the $(a b)$ plane (i.e., plane defined by talc sheets).

Natural talc is used in many industrial applications, in particular as filler in composite materials in order to reduce the production costs and possibly to improve their physical and chemical properties (Claverie et al. 2017). However, natural talc has important limitations. It contains minor or trace elements (Martin et al. 1999), and is often associated with other minerals like chlorite, chrysotile, pyrite, graphite, calcite or amphibole. Furthermore, industrial applications usually require small and homogeneous particles. This cannot be achieved by grinding natural talc since the crystal structure becomes amorphized. These limitations were circumvented by developing a new process to synthesize sub-micron talc particles (Dumas et al. 2013a, b, 2016; Claverie et al. 2017). These syntheses produce a single-phased chemically pure product from a short hydrothermal treatment (from a few seconds to few hours). Providing talc products of accurately controlled chemical compositions, and at the same time, an inexpensive and convenient method to verify this composition would increase the industrial applications. In this aim, we investigate here the Mg-Ni series by infrared spectroscopy, building on the work by Dumas et al. (2015). This previous study focused on the transformation mechanism from the amorphous talc precursor to crystalline synthetic talc, using samples with $50 \%$ and $100 \%$ Ni substitution.

We report here the infrared spectroscopic investigation of synthetic talc samples with five compositions spanning the entire $\mathrm{Mg}-\mathrm{Ni}$ solid solution. The measured spectra are discussed in light of the modeling of the infrared spectra of Mg-Ni talcs from first-principles 


1

calculations based on the density function theory. A special attention is given to the absorption bands related to $\mathrm{OH}$ stretching vibrations in the near- and mid-infrared regions, since $\mathrm{OH}$ groups of talc are known to be a good probe of the local chemical environment (e.g., Wilkins and Ito 1967; Petit et al. 2004; Martin et al. 2006). Since the pioneer work of Wilkins and Ito (1967), the four $\mathrm{OH}$ absorption bands observed in binary octahedral solid solutions of talc are assigned to $\mathrm{OH}$ groups characterized by their specific cationic environment. These bands can be used to derive the chemical composition of talc and to discuss the distribution of the magnesium and the substituting ion between the two crystallographically distinct octahedral sites. The present theoretical modeling of infrared spectra provides new insights on these applications. Sub-micron talc particles are characterized by a large proportion of edge surfaces with many reactive sites. This explains the observed hydrophilic character of synthetic talc compared to the well-know hydrophobicity of natural talc (Dumas et al. 2013c, 2016; Claverie et al. 2017). In order to improve our understanding of the infrared spectra of synthetic talcs, we also modeled the infrared signature of $\mathrm{OH}$ and $\mathrm{H}_{2} \mathrm{O}$ adsorbed on particle edge sites.

\section{Materials and methods}

\subsection{Samples preparation}

The starting materials for the co-precipitation experiments were magnesium acetate tetrahydrate $\left(\mathrm{Mg}\left(\mathrm{CH}_{3} \mathrm{COO}\right)_{2} \cdot 4 \mathrm{H}_{2} \mathrm{O}\right)$, nickel acetate tetrahydrate $\left(\mathrm{Ni}\left(\mathrm{CH}_{3} \mathrm{COO}\right)_{2} \cdot 4 \mathrm{H}_{2} \mathrm{O}\right)$, sodium metasilicate pentahydrate $\left(\mathrm{Na}_{2} \mathrm{SiO}_{3} \cdot 5 \mathrm{H}_{2} \mathrm{O}\right)$, sodium acetate trihydrate $\left(\mathrm{NaCH}_{3} \mathrm{COO} \cdot 3 \mathrm{H}_{2} \mathrm{O}\right)$, and acetic acid. All reagents were purchased from Aldrich and used 
without any further purification. A $1 \mathrm{~N}$ solution of glacial acetic acid was prepared using deionized water.

Five samples of synthetic talc (labeled Ni0, Ni25, Ni50, Ni75 and Ni100, according to the mol \% Ni targeted) were prepared using the process describes in patent of Dumas et al. (2013a. b). Synthetic talc preparation was achieved in two steps. First, a talc precursor was prepared at room temperature and atmospheric pressure with the right $(\mathrm{Mg}+\mathrm{Ni}) / \mathrm{Si}$ talc ratio (Table 1). Second, a hydrothermal treatment at $300{ }^{\circ} \mathrm{C}$ and 86 bar during $6 \mathrm{~h}$ transformed the precursor into synthetic talc. Before analysis, samples were centrifuged and rinsed to remove any traces of sodium acetate salt.

\subsection{Characterization}

X-ray diffraction analysis (XRD) was performed on dried talc powders using the sideloading procedure to minimize preferential orientations. The XRD patterns were recorded on a Bruker D2 Phaser diffractometer over the $0-80^{\circ} 2 \theta \mathrm{CuK} \alpha_{1+2}$ angular range, with a step size of $0.02^{\circ} 2 \theta$ and a 0.5 s count time per step.

The Fourier transformed infrared spectroscopy in the near-infrared region was recorded with 32 scans at a resolution of $4 \mathrm{~cm}^{-1}$ between 4,000 and $10,000 \mathrm{~cm}^{-1}$ using a Thermo Nicolet 6700 FTIR spectrometer (Services Communs de Chimie, UPS, University of Toulouse) with a smart NIR Integrating Sphere (CaF2 beam splitter and InGaAs detector). No specific sample preparation was needed.

Mid-infrared spectra were recorded with a Thermo Nicolet 6700 FTIR spectrometer equipped with a DLaTGS detector using a transmission mode. The spectral conditions consisted in a resolution of $4 \mathrm{~cm}^{-1}$ between 400 and $4,000 \mathrm{~cm}^{-1}$ using 16 scans. Sample powders were diluted into $\mathrm{KBr}$ pellets. 
Regions of $\mathrm{OH}$ stretching modes were analyzed using the Fityk program (Wojdyr

115 2010) to decompose the infrared signal into pseudo-Voigt components. The baseline was

116 defined around the two regions where vibrational modes are related to structural $\mathrm{OH}$ groups

117 (i.e., $6900-7300 \mathrm{~cm}^{-1}$ in near-infrared and $3610-3730 \mathrm{~cm}^{-1}$ in mid-infrared, respectively).

118 During the decomposition, the number of components was kept as minimal as possible.

\subsection{Computational methods}

Structural relaxations and calculation of vibrational properties were performed within the framework of the density functional theory (DFT), using periodic boundary conditions and the generalized gradient approximation (GGA) to the exchange-correlation functional, with the PBE parameterization (Perdew et al. 1996). The ionic cores were described using the latest version of ultrasoft pseudopotentials from the GBRV library (Garrity et al. 2014). Wave functions and charge density were expanded in plane-waves with 40 and 240 Ry cutoffs, the electronic integration, the Brillouin zone of the triclinic talc unit cell (space group $C-1$ ) was sampled using a shifted $4 \times 2 \times 2 k$-points grid. For Ni-bearing talc, calculations were

130 spin-polarized and set up to the ferromagnetic structure. The structure relaxations and 131 vibrational mode calculations were done using the PWscf and PHonon codes of the Quantum 132 ESPRESSO package (Giannozzi et al., 2009; http://www.quantum-espresso.org). During the

133 relaxations, forces on atoms were minimized to less than $10^{-4}$ Ry/a.u. Transmission infrared

134 spectra were calculated using an electrostatic model similar to the one developed by Balan et 135 al. (2001, 2008). This approach is based on the ab initio calculation of the low-frequency 136 dielectric tensor, which requires the frequencies and atomic displacements of the normal 137 vibrational mode and dielectric quantities (Born effective charges and electronic dielectric 138 tensor), all computed within the harmonic approximation using the linear response theory 
139 (Baroni et al. 2001) as implemented in the PHonon code. In order to avoid the divergence of

140 the low-frequency dielectric tensor at the resonance frequencies, we used a damping 141 coefficient arbitrarily fixed to $2 \mathrm{~cm}^{-1}$ (cf Equation 1 of Balan et al. 2001).

142 Talc unit cell contains six Mg atoms in the octahedral sheet. In order to investigate the 143 Mg-Ni series, starting from this pure Mg-talc, we substituted one, three, five or six $\mathrm{Mg}$ atoms 144 by $\mathrm{Ni}$ atoms, leading to structural models corresponding to talcs with $\mathrm{Ni}$ concentrations of $1450.0,16.7,50.0,83.3$ or $100.0 \mathrm{~mol} \%$, respectively (the theoretical models were labeled Ni0, 146 Ni17, Ni50, Ni83 and Ni100, respectively).

147 In addition to the investigation of the vibrational properties of bulk Mg-Ni talcs, we 148 also explored the infrared signature of hydroxyl groups and water molecules remaining 149 adsorbed on edge sites of small talc particles even after drying of talc powders. To this aim, 150 we also built two surface models (surfaces (100) and (010)) for the two end members of the 151 Mg-Ni series. We adopted a supercell approach, in which a slab bounded by either (100) or 152 (010) surfaces was cut from the optimized bulk structure of either Mg-talc or Ni-talc. Slabs 153 were cut in a manner for preserving the tetrahedral coordination of $\mathrm{Si}$ atoms and the 154 octahedral coordination of $\mathrm{Mg}$ or $\mathrm{Ni}$ atoms. Protons were then added to surface $\mathrm{O}$ atoms in 155 order to compensate the O charge, which leads to neutral slabs containing 92 or 99 atoms for 156 the (010) or (100) surfaces, respectively. The slab surfaces were separated from their adjacent 157 images by a vacuum gap of at least $9 \AA$. The four triclinic simulation cells have the following $158 \mathrm{X}, \mathrm{Y}, \mathrm{Z}$ dimensions: $21.40 \AA, 9.27 \AA, 10.12 \AA$ for the (100) surface of Mg-talc, $5.35 \AA, 27.80$ $159 \AA, 10.12 \AA$ for the (010) surface of Mg-talc, $21.31 \AA, 9.24 \AA, 9.67 \AA$ for the (100) surface of 160 Ni-talc, and $5.33 \AA, 27.72 \AA, 9.67 \AA$ for the (010) surface of Ni-talc. Surface relaxation was 161 performed at constant volume and with a Brillouin zone sampling reduced to a single point in 162 the direction perpendicular to the surface. Vibrational properties were computed only for $\mathrm{OH}$ 163 stretching modes. 
3. Results and discussion

\subsection{Structural properties}

X-ray diffraction patterns were collected on the five synthetic talc samples (Fig. S1).

Each pattern shows inter-reticular distances characteristic of 001,003 and $02 l-11 l$ reflections of talc structure (e.g., Dumas et al. 2015). No other mineral phase is detected. One can note that 001 and 003 peaks become sharper and more intense with increasing Ni content, which reflects a progressive increase in the crystallinity degree, as previously observed by Martin et al. (1992).

Table 2 compares the experimental and DFT-optimized values of cell parameters and mean bond lengths for the $\mathrm{Mg}$ end member of talc. In our calculations, $a$ and $b$ cell parameters are overestimated by $1 \%$ while $\alpha, \beta, \gamma$ angles are slightly underestimated by less

178 than $0.4 \%$. These trends are similar to those observed by Ulian et al. (2013). The only

179 discrepancy is the significant overestimation of the $c$ cell parameter but this larger interlayer 180 space does not affect the interatomic bond lengths that are only $1 \%$ larger than their 181 experimental counterparts. It is well known that standard DFT does not capture accurately van 182 der Waals interactions that govern the cohesion of talc layers. However, Larentzos et al. 183 (2007) already demonstrated that first-principles calculations using DFT-GGA functionals are 184 sufficiently accurate in predicting the mineral structure and vibrational properties of talc. In the solid solution of interest, $\mathrm{Mg}$ atoms are progressively substituted by $\mathrm{Ni}$ atoms in 186 octahedral sites. Because the ionic radius of $\mathrm{Ni}^{2+}(69 \mathrm{pm})$ is slightly smaller than the one of $187 \mathrm{Mg}^{2+}(72 \mathrm{pm})$, we obtain a mean Ni-O bond length $(2.07 \AA$ in the Ni100 model) slightly 188 shorter than the mean $\mathrm{Mg}-\mathrm{O}$ bond length (2.09 $\AA$ in the Ni0 model). This decrease is in 
agreement with the values derived experimentally $(2.055 \AA$ for the $\mathrm{Ni}$-talc according to the

190 EXAFS analysis of Dumas et al. 2015, and $2.071 \AA$ for the Mg-talc according to Rietveld refinement of X-ray diffraction patterns on large Mg natural talc single crystal of Perdikatsis

192

193

194

195 and Burzlaff 1981). Thus the Mg-Ni substitution leads to a slight contraction of the crystal lattice. Cell parameters $a$ and $b$ decrease from $5.35 \AA$ to $5.33 \AA$, and from $9.27 \AA$ to $9.24 \AA$, respectively (Fig. 1).

\subsection{Infrared spectra of Mg-talc and Ni-talc}

Experimental infrared spectra of Mg-talc (sample Ni0) and Ni-talc (sample Ni100) are shown in Figure 2. The higher degree of crystallinity of Ni-talc already mentioned from the X-ray diffraction patterns is also visible in infrared spectroscopy. Absorption bands are sharper in Ni-talc. Above $3000 \mathrm{~cm}^{-1}$, spectra are characterized by a broad band with its maximum at $3438 \mathrm{~cm}^{-1}$ and a sharp band at higher frequency $\left(3677 \mathrm{~cm}^{-1}\right.$ in $\mathrm{Mg}$-talc and 3627 $\mathrm{cm}^{-1}$ in Ni-talc). Below $1200 \mathrm{~cm}^{-1}$, we can observe three groups of absorption bands at about 1000,700 and $450 \mathrm{~cm}^{-1}$. The striking difference between the spectra of Mg-talc and Ni-talc is in the group of bands around $700 \mathrm{~cm}^{-1}$. Mg-talc displays a unique band at $670 \mathrm{~cm}^{-1}$ while Nitalc shows two bands at $668 \mathrm{~cm}^{-1}$ and $710 \mathrm{~cm}^{-1}$.

Infrared spectra have also been computed from first-principles calculations on models $\mathrm{Ni0}$ and Ni100, taking into account the shape of talc particles. Indeed, for particles smaller than the infrared wavelength (sub-micron particles), the electric field (depolarization field) induced by surface charges in the polarized particles shifts the absorption bands and affects their intensity with respect to the resonances of the dielectric tensor of the bulk mineral (e.g., Balan et al. 2008a). These resonances of the dielectric tensor correspond to the spectra at the bottom of Figure 2. Three particle shapes have been considered: a plate perpendicular to the $c^{*}$ axis, a sphere and an intermediate shape (oblate spheroid). The correspondence between 
214 theoretical and experimental absorption bands is straightforward (Fig. 2). For Mg-talc, the 215 plate shape provides the best description of the bands observed at 670,538 and $450 \mathrm{~cm}^{-1}$, and 216 in particular their spacings. For Ni-talc, only the plate shape gives the right ratio of intensity 217 between the two bands at 668 and $710 \mathrm{~cm}^{-1}$ and in the same time, the intense and rather 218 symmetric band at $1030 \mathrm{~cm}^{-1}$. This suggests that the particles of the synthetic sub-micron talc 219 samples reflect their layered structure and probably have only few talc sheets. A large staking of talc sheets relative to the lateral extension of the particle would approach the sphere model instead.

Looking at the theoretical vibrational modes enables us to assign the observed absorption bands. The sharp band above $3600 \mathrm{~cm}^{-1}$ corresponds to the stretching vibration of the structural $\mathrm{OH}$ groups. The difference in wavenumber between calculated and observed $\mathrm{OH}$ bands is at least partly explained by the anharmonicity. $\mathrm{OH}$ stretching vibrations show a certain degree of anharmonicity while calculations are performed within the harmonic approximation. The broad band around $3438 \mathrm{~cm}^{-1}$ is not related to the talc structure. It is usually assigned to weakly bound water and will be discussed further. The normal mode calculated at about $900 \mathrm{~cm}^{-1}$ (bottom spectrum of Fig. 2) corresponds to a Si-O stretching mode polarized along the $c^{*}$ axis while the more intense band calculated at $\sim 980 \mathrm{~cm}^{-1}$ is due to two degenerated Si-O stretching modes polarized in the $(a b)$ plane. For the plate shape, the

232 band at $\sim 980 \mathrm{~cm}^{-1}$ remains at the same position while the band at $\sim 900 \mathrm{~cm}^{-1}$ shifts to higher 233 wavenumbers. The two bands become superimposed in Ni-talc, which contributes to the 234 strong intensity and symmetry of the band observed at $1030 \mathrm{~cm}^{-1}$. While in $\mathrm{Mg}$-talc, the mode 235 polarized along the $c^{*}$ axis appears at even higher wavenumber than the modes polarized in 236 the $(a b)$ plane, thus explaining the asymmetric shape of the band observed at $1018 \mathrm{~cm}^{-1}$ with a 237 shoulder at $\sim 1060 \mathrm{~cm}^{-1}$. At lower wavenumber, the band at $670 \mathrm{~cm}^{-1}$ in $\mathrm{Mg}$-talc and $710 \mathrm{~cm}^{-1}$ 238 in Ni-talc corresponds to $\mathrm{OH}$ libration motions. Our analysis of the theoretical data also 
shows that in Ni-talc, even if the band observed at $668 \mathrm{~cm}^{-1}$ appears in the same region, the

240 vibrational mode involved is fundamentally different. This band corresponds to a lattice mode 241 polarized along the $\mathrm{c}^{*}$ axis and involving $\mathrm{Ni}, \mathrm{O}$ and $\mathrm{H}$ atoms. In $\mathrm{Mg}$-talc, the same mode

242 (involving now $\mathrm{Mg}, \mathrm{O}, \mathrm{H}$ atoms) gives rise to the band observed at $538 \mathrm{~cm}^{-1}$. Finally, the 243 most intense doublet at $\sim 450,467 \mathrm{~cm}^{-1}$ is assigned to lattice modes polarized in the $(a b)$ 244 plane and involving all atoms.

\subsection{Infrared spectra of $\mathrm{OH}$ stretching bands in the Mg-Ni series}

Figure 3 reports the measured near-infrared and mid-infrared spectra in the range of the first overtones and fundamentals $\mathrm{OH}$ stretching modes for the five synthetic samples. Both spectra look very similar with the presence of up to four main absorption bands. The 250 decomposition of all spectra required considering, in addition to these four bands, two less 251 intense contributions on the high frequency side (at 7226 and $7206 \mathrm{~cm}^{-1}$ for the first overtones, and at 3716 and $3687 \mathrm{~cm}^{-1}$ for the fundamental modes). These contributions were assigned to $\mathrm{OH}$ groups on sheet edges by Dumas et al. (2013c). The spectra decompositions 254 can be found in supplementary information (Figs. S2 and S3), and the derived data for the 255 four main $\mathrm{OH}$ bands are compiled in Table 3. These absorption bands remain nearly at the 256 same wavenumbers over the entire solid solution (at $3677,3662,3646$ and $3627 \mathrm{~cm}^{-1}$ for the 257 fundamental modes). However, as reported by Wilkins and Ito (1967) for well-crystallized 258 synthetic samples, a closer look indicates that the separation between bands slightly decreases 259 when $\mathrm{Ni}$ content increases. This variation does not exceed $3 \mathrm{~cm}^{-1}$ over the entire 260 compositional range. It is possible to assess the anharmonicity of $\mathrm{OH}$ vibrations from the 261 wavenumbers of fundamental modes $\left(W_{\nu \mathrm{VH}}\right)$ and first-overtones $\left(W_{2 v_{\mathrm{OH}}}\right)$, by calculating the 262 anharmonicity constant, $X=W_{2 \vee O H} / 2-W_{\nu O H}$ (Bourdéron and Sandorfy 1973). Results are 263 given in Table 3. Considering the standard deviations, we found the anharmonicity constant to 
264 be the same for all $\mathrm{OH}$ stretching modes and for all compositions, $X=-85.0 \pm 2.2 \mathrm{~cm}^{-1}(2 \sigma)$. It

265 is in good agreement with the value found by Petit et al. (2004b) for various natural and 266 synthetic talcs, $X=-86.0 \pm 2.5 \mathrm{~cm}^{-1}$. The anharmonicity constant being independent on the 267 clay chemistry, these authors could apply this relation in order to improve the interpretation of 268 the near-infrared spectra of other phyllosilicates like smectite and kaolinite polymorphs.

Figure 3 also shows the theoretical spectra obtained for the talc models considered.

270 Talc unit cell contains six octahedral sites (2 M1 sites and 4 M2 sites). For the Ni17 model, 271 one Ni atom was placed in either M1 or M2 site. The two spectra are equivalent. In a similar 272 manner, the Ni83 model corresponds to one Mg atom placed in either M1 or M2 site, which leads to the same spectrum. For the Ni50 model, several configurations of the three Ni atoms 274 over the six octahedral sites have been tested, and the two spectra obtained are shown in 275 Figure 3. Theoretical spectra, like measured ones, display up to four absorption bands. We 276 can already note that the distribution of the cations on the octahedral sites affects significantly 277 the infrared spectrum (number of bands and their intensities). For a given composition, the 278 limited size of the simulation cell imposes an ordered cation distribution that does not reflect 279 the distribution occurring in synthetic or natural samples. This explains the differences 280 observed between experimental and theoretical spectra in figure 3. Wavenumbers and 281 absorbances derived from the theoretical spectra are listed in Table 4. Talc unit cell contains 282 four hydroxyl groups. Due to their position perpendicular to the layers, all OH stretching 283 modes are polarized along the $c^{*}$ axis. Each hydroxyl group is bonded to three octahedral 284 cations. In order to know which hydroxyl group is involved in each vibrational mode, we 285 calculated the displacement of each of these four $\mathrm{H}$ atoms (Table 4). Results confirm 286 unambiguously the assignment of the four mains absorption bands. From high to low 287 frequency, the four bands correspond to the stretching vibration of hydroxyl groups bonded to $2883 \mathrm{Mg}, 2 \mathrm{Mg} 1 \mathrm{Ni}, 1 \mathrm{Mg} 2 \mathrm{Ni}$, and $3 \mathrm{Ni}$ atoms. The present data also demonstrate that there is no 
coupling between hydroxyl groups with distinct cationic environments. These conclusions fully support the interpretation of Wilkins and Ito (1967).

\subsection{Water adsorption on edge sites}

Natural talc is known to be hydrophobic in relation with its sheet-like morphology of few tens of micrometers wide (Fig. 4). Indeed the very large basal hydrophobic surface dominates over the lateral surfaces (sheet edges), which display however many reactive sites and a hydrophilic behavior. Talc particles synthesized here conserve their sheet-like morphology but present sub-micron sizes. As illustrated in figure 4, the particles size decreases drastically and concomitantly the proportion of sheet edges increases making the hydrophilic behavior measurable. This is clearly evidenced by thermogravimetric analyses (Dumas et al. 2013c). While natural talc has a single loss of weight around $950{ }^{\circ} \mathrm{C}$ corresponding to its destabilization, synthetic sub-micron talc undertakes two additional losses before 150 and $450{ }^{\circ} \mathrm{C}$, attributed first to physisorbed water and second to silanols (Si$\mathrm{OH})$ and magnesium hydroxides $(\mathrm{Mg}-\mathrm{OH})$ on the sheet edges. This previous study employed spectroscopic techniques (nuclear magnetic resonance and infrared spectroscopies) to access the edges contributions of synthetic sub-micron Mg-talc. In ${ }^{1} \mathrm{H}$ NMR spectra, two new narrow and distinct peaks were interpreted as associated to physisorbed water and silanol groups. In near-infrared spectra, two small contributions at 7200 and $7230 \mathrm{~cm}^{-1}$ (next to the band at 7185 $\mathrm{cm}^{-1}$ of structural $\mathrm{OH}$ groups) were assigned to $\mathrm{OH}$ groups on edge sites, i.e. $\mathrm{Si}-\mathrm{OH}$ and $\mathrm{Mg}-$ $\mathrm{OH}$ respectively. In order to investigate further the influence of sheet edges on the infrared spectra, we built surface models with several distinct hydroxyl groups ( $\mathrm{OH}$ bonded to one $\mathrm{Si}$, to one $\mathrm{Si}$ and one $\mathrm{Mg}$, or to two $\mathrm{Mg}$ ) and water molecules chemisorbed on a $\mathrm{Mg}$ site (Fig. 5). These models do not consider physisorbed water molecules. 
314 molecule desorbed. This molecule was removed before calculating the vibrational properties.

315 Therefore the surface relaxation differs between Ni-talc and Mg-talc. The final arrangement 316 of hydroxyl groups is different. Results analysis indicates that hydroxyl groups pointing 317 outward vibrate at a frequency close to the structural hydroxyl groups. On the contrary, Si-OH 318 groups pointing toward another talc layer or $\mathrm{OH}$ groups pointing toward another $\mathrm{O}$ atom of 319 the sheet edge vibrate at lower frequency. The stronger the hydrogen bond formed, the lower 320 the frequency of the associated absorption band. These results suggest that the observed broad 321 band centered at $3440 \mathrm{~cm}^{-1}$ is due not only to the physisorbed water molecules (not modeled 322 here) but also to the multitude of geometries of hydroxyls chemically adsorbed on edge sites. 323 In experimental studies investigating the infrared absorption bands related to structural $\mathrm{OH}$ 324 groups, the spectrum baseline is defined in such a way that the contribution of the broad band 325 is removed but small features remain on the high-frequency side. As mentioned above, 326 Dumas et al. (2013c) looked at these small bands in the near-infrared region for synthetic $\mathrm{Mg}$ 327 talc. Above the structural $\mathrm{OH}$ band $\left(7185 \mathrm{~cm}^{-1}\right)$, the two weak bands at 7200 and $7230 \mathrm{~cm}^{-1}$ 328 were assigned to $\mathrm{Si}-\mathrm{OH}$ and $\mathrm{Mg}-\mathrm{OH}$ respectively. It is worth mentioning that, in the mid329 infrared region, our calculations lead to similar features. Above the structural $\mathrm{OH}$ band 330 calculated at $3848 \mathrm{~cm}^{-1}$, we found two weak bands at 3873 and $3885 \mathrm{~cm}^{-1}$ related to Si-OH 331 and $\mathrm{Mg}_{2}-\mathrm{OH}$ groups respectively.

\subsection{Quantification of the chemical composition}

The four main $\mathrm{OH}$ stretching bands are now unambiguously attributed to specific structural $\mathrm{OH}$ groups defined by their cationic environment. For the mid-infrared region, the

336 bands at $3677,3662,3646$ and $3627 \mathrm{~cm}^{-1}$ are related to hydroxyl groups bonded to $3 \mathrm{Mg}$, 
338 bands (i.e. ratio of bands areas) to quantify the concentration of each of the hydroxyl types

339 and therefore the chemical composition of the talc, one has to assume that the absorption

340 coefficients of these different hydroxyls are the same whatever the local chemistry around $\mathrm{OH}$

341 groups. This is generally assumed in most experimental studies (e.g., Petit et al. 2004a).

342 However it has been shown (Balan et al. 2008b) that considering many minerals, absorption

343 coefficients of $\mathrm{OH}$ stretching modes globally decrease with increasing frequency. This

344 assumption of constant absorption coefficients can be checked from our theoretical study.

345 Theoretical molar absorption coefficients, $K_{\text {int }}$, and the relative integrated absorbances

346 for each vibrational mode (i.e. each $\mathrm{OH}$ band) are given in Table 4 . We can note that with a

347 mean value of $K_{\text {int }}=9071 \mathrm{Lmol}^{-1} \mathrm{~cm}^{-2}$, the talc $\mathrm{OH}$ groups have an absorption coefficient

348 similar as inner $\mathrm{OH}$ groups of lizardite and clinochlore (Balan et al. 2008b). Most

349 importantly, if we look at the relative absorbance of each $\mathrm{OH}$ band for a given sample, we see

350 variations, but these variations do not follow systematic trends. In model Ni17, both bands

351 contribute almost equally to the total absorbance. In model Ni50a, bands with lower

352 wavenumbers contribute slightly more (up to $26.8 \%$ ) than bands with higher wavenumbers

353 (down to 22.4\%). But this trend is opposite in model Ni83. We can consider these variations

354 either as inherent to the configurations investigated or due to the uncertainty of the calculation

355 (absorption coefficients are properties extremely sensitive to the structural optimization). To

356 clarify this point, we estimate the composition of these fully constrained models from these

357 values of relative absorbance. Table 5 shows for instance for the model Ni50a, that the

358 calculated relative absorbances lead to a composition of $52.5 \mathrm{~mol} \% \mathrm{Ni}$, different from the

359 expected $50 \mathrm{~mol} \% \mathrm{Ni}$ that one obtains if $\mathrm{OH}$ band contributes equally to the total absorbance.

360 The present theoretical results suggest that the small observed variations are related to

361 computational uncertainties and therefore that the assumption of a constant absorption

362 coefficient whatever the cationic environment around the hydroxyls is correct. 
The procedure is applied to the synthetic samples and talc compositions obtained from

364 the relative integrated absorbances of either the fundamental modes or the first-overtone modes are compared (Table 6). Assuming that during the synthesis process, all nickel is incorporated into the talc particles, we find that results from the near-infrared region are sensibly better than those from the mid-infrared region. They provide the correct composition within 2 mol \%. Only sample Ni100 shows a larger difference of 6 mol \% between the expected composition and the one derived from infrared spectroscopy. While no magnesium is used in the synthesis of this sample, both near- and mid-infrared spectra display a weak band (at $7123 \mathrm{~cm}^{-1}$ and $3646 \mathrm{~cm}^{-1}$ respectively), which could be attributed, according to its

372 position, to $\mathrm{OH}$ groups bonded to one $\mathrm{Mg}$ and two $\mathrm{Ni}$ atoms. Note that Dumas et al. (2015) 373 already reported the presence of such weak band for the Ni end-member of a similar synthetic 374 sub-micron talc. The presence of this weak band either reflects a contamination during the 375 synthesis or a wrong assignment. An electron microprobe analysis was performed on this

376 Ni100 sample and leads to a Ni proportion of $98.8 \pm 0.2 \mathrm{~mol} \%$, incompatible with the 94 mol $377 \%$ derived from infrared spectroscopy. Therefore the weak band at $7123 \mathrm{~cm}^{-1}$ cannot be 378 explained by a Mg contamination. As suggested by the calculated spectra of surface models 379 for Ni-talc (Fig. 5), this weak band is rather related to $\mathrm{OH}$ groups on edge sites, like Ni-OH or $380 \mathrm{Si}-\mathrm{OH}$. This assignment is also supported by the fact that a band located at a similar 381 wavenumber $\left(7121 \mathrm{~cm}^{-1}\right)$ was previously observed by Christy (2010) on a silica gel surface.

\section{$383 \quad 3.6$ Cationic distribution}

384 The infrared spectroscopic data can also be used to discuss the distribution of cations 385 in the octahedral sheet (Petit et al. 2004a). If $\mathrm{Mg}$ and $\mathrm{Ni}$ atoms are randomly distributed, the 386 four $\mathrm{OH}$ bands should occur with the probabilities specified in Table 7. It is therefore possible 387 to calculate the relative integrated absorbances that one expects for a given composition and a 
random distribution of octahedral cations. These values are compared with the relative

389 absorbances obtained by spectral decomposition in Table 7 and Figure 6. The good 390 correlation observed in Figure 6 indicates that divalent cations are randomly distributed in the

391 octahedral sheets of these synthetic sub-micron talc samples like in the various natural 392 samples investigated by Petit et al. (2004a). This conclusion is supported by our DFT 393 calculations, which predict that nickel has no preference for M1 and M2 octahedral sites. The 394 energy difference $(0.3 \mathrm{~kJ} / \mathrm{mol})$ is one order of magnitude smaller than the thermal energy at 395 ambient temperature.

\section{Conclusion}

This combined experimental and theoretical infrared spectroscopic study allowed us to characterize further a synthetic talc product with potential industrial applications. Over the whole range of the $\mathrm{Mg}-\mathrm{Ni}$ solid solution, the sub-micron talc particles present: (i) a random distribution of $\mathrm{Mg}$ and $\mathrm{Ni}$ cations in the octahedral sheets, (ii) platy shapes nicely reflecting their layered structure, and (iii) an interesting hydrophilic character related to the large proportion of sheet edges. The Mg-Ni substitution is also accompanied by an increase in the crystallinity degree.

The confrontation of measured and calculated infrared spectra enabled to fix the 408 spectra interpretation to firm physical basis. Absorption bands below $1200 \mathrm{~cm}^{-1}$ have been 409 assigned to the corresponding vibrational modes, allowing us to understand the differences 410 observed between $\mathrm{Mg}$-talc and $\mathrm{Ni}$-talc. In the $\mathrm{OH}$ stretching region related to structural 411 hydroxyl groups, our calculations show no coupling between the stretching modes of $\mathrm{OH}$ 412 groups distinguishable by their cationic environment. Results thus fully support the 
assignment made by Wilkins and Ito (1967). We have also demonstrated that absorption

414 coefficients of $\mathrm{OH}$ groups are constant whatever the cationic environment of these hydroxyls.

415 This validates the key assumption for quantifying the talc composition from the relative 416 absorbance of $\mathrm{OH}$ bands.

417 The surface models considered here suggest that the infrared signatures of hydroxyls 418 adsorbed on the reactive sites of sheet edges fall in the same wavenumber range as the broad 419 band assigned to physisorbed water molecules (band observed between 3000 and $3700 \mathrm{~cm}^{-1}$ ). 420 In more details, the bands related to the most weakly hydrogen-bonded $\mathrm{OH}$ surface groups are 421 located in the same range as the bands attributed to $\mathrm{OH}$ structural groups. This observation 422 might hinder the accurate determination of talc composition. However absorption bands 423 related to $\mathrm{OH}$ surface groups have relatively weak intensities and do not affect the infrared424 derived composition by more than a few percent.

Acknowledgments Calculations were performed using HPC resources from CALMIP (Grant 2017-P1037). Salary of Louise Delon (3rd year student of UPSSITECH School, Toulouse) was supported by IMERYS group. We thank L. Menjot, C. Routaboul and Ph. de Parseval for their help in XRD, IR, and EMP measurements, respectively.

\section{References}

434 Balan E, Saitta AM, Mauri F, Calas G (2001) First-principles modeling of the infrared spectrum of kaolinite. Am Mineral 86:1321-1330 
436 Balan E, Blanchard M, Hochepied J-F, Lazzeri M (2008a) Surface modes in the infrared spectrum of hydrous minerals: the $\mathrm{OH}$ stretching modes of bayerite. Phys Chem Miner $35: 279-285$

Balan E, Refson K, Blanchard M, Delattre S, Lazzeri M, Ingrin J, Mauri F, Wright K, Winkler B (2008b) Theoretical infrared absorption coefficient of $\mathrm{OH}$ groups in minerals. Am Mineral 93:950-953

Baroni S, de Gironcoli S, Dal Corso A, Giannozzi P (2001) Phonons and related crystal properties from density-functional perturbation theory. Rev Modern Phys 73:515-561

Bourdéron C, Sandorfy C (1973) Association and the assignment of the $\mathrm{OH}$ overtones in hydrogen-bonded alcohols. J Chem Phys 59:2527-2536

Christy AA (2010) New insights into the surface functionalities and adsorption evolution of water molecules on silica gel surface: A study by second derivative near infrared spectroscopy. Vib Spectrosc 54:42-49

Claverie M, Dumas A, Careme C, Poirier M, Le Roux C, Micoud P, Martin F, Aymonnier C (2017) Synthetic talc and talc-like structures : preparation, features and applications. Chemistry: A European Journal 23:2-26

Dumas A, Le Roux C, Martin F, Micoud P (2013a) Process for preparing a composition comprising synthetic mineral particles and composition. WO2013004979 A1

Dumas A, Le Roux C, Martin F, Micoud P (2013b) Procédé de préparation d'une composition comprenant des particules minérales synthétiques et composition. FR2977580 A1

Dumas A, Martin F, Le Roux C, Micoud P, Petit S, Ferrage E, Brendlé J, Grauby O, Greenhill-Hooper M (2013c) Phyllosilicates synthesis: a way of accessing edges contributions in NMR and FTIR spectroscopies. Example of synthetic talc. Phys Chem Minerals 40:361-373 
Dumas A, Mizrahi M, Martin F, Requejo FG (2015) Local and extended-order evolution of synthetic talc during hydrothermal synthesis: Extended X-ray absorption fine structure, X-ray diffraction, and fourier transform infrared spectroscopy studies. Cryst Growth Des 15:5451-5463

464

Dumas A, Claverie M, Slostowski C, Aubert G, Careme C, Le Roux C, Micoud P, Martin F, Aymonier C (2016) Fast-Geomimicking using Chemistry in Supercritical Water. Angew Chem 128:1-5

Garrity KF, Bennett JW, Rabe KM, Vanderbilt D (2014) Pseudopotentials for highthroughput DFT calculations. Comput Mater Sci 81:446-452

Giannozzi P, Baroni S, Bonini N, Calandra M, Car R, Cavazzoni C, Ceresoli D, Chiarotti GL, Cococcioni M, Dabo I, Dal Corso A, de Gironcoli S, Fabris S, Fratesi G, Gebauer R, Gerstmann U, Gougoussis C, Kokalj A, Lazzeri M, Martin-Samos L, Marzari N, Mauri F, Mazzarello R, Paolini S, Pasquarello A, Paulatto L, Sbraccia C, Scandolo S, Sclauzero G, Seitsonen AP, Smogunov A, Umari P, Wentzcovitch RM (2009) Quantum ESPRESSO: a modular and open-source software project for quantum simulations of materials. J. Phys.: Condens. Matter 21:395502

Larentzos JP, Greathouse JA, Cygan RT (2007) An ab initio and classical molecular dynamics investigation of the structural and vibrational properties of talc and pyrophyllite. J Phys Chem C 111:12752-12759

Martin F, Petit S, Decarreau A, Grauby O, Hazemann J-L, Noack Y (1992) Experimental study of Si-Ge tetrahedral solid solution in Ni-Co-Mg talcs. Thin Solid Films 222:189195

Martin F, Micoud P, Delmotte L, Maréchal L, Le Dred R, de Parseval ph, Mari A, Fortuné JP, Salvi S, Béziat D, Grauby O, Ferret J (1999) The structural formula of talc from the Trimouns deposit, Pyrénées, France. Can Mineral 37:975-984 
486 Martin F, Ferrage E, Petit S, de Parseval Ph, Delmotte L, Ferret J, Arseguel D, Salvi S (2006) Fine probing the crystal-chemistry of talc by MAS NMR spectroscopy. Eur J Mineral $18: 641-651$

Perdew JP, Burke K, Ernzerhof M (1996) Generalized gradient approximation made simple. Phys Rev Lett 77:3865-3868

Perdikatsis B, Burzlaff $\mathrm{H}$ (1981) Strukturverfeinerung am talk $\mathrm{Mg}_{3}\left[(\mathrm{OH})_{2} \mathrm{Si}_{4} \mathrm{O}_{10}\right]$. Zeitschrift für Kristallographie 156:177-186

Petit S, Martin F, Wiewiora A, De Parseval P, Decarreau A (2004a) Crystal-chemistry of talc: A near infrared (NIR) spectroscopy study. Am Mineral 89:319-326

Petit S, Decarreau A, Martin F, Robert R (2004b) Refined relationship between the position of the fundamental $\mathrm{OH}$ stretching and the first overtones for clays. Phys Chem Minerals 31:585-592

Ulian G, Tosoni S, Valdrè G (2013) Comparison between Gaussian-type orbitals and plane wave $a b$ initio density functional theory modeling of layer silicates: Talc $\left[\mathrm{Mg}_{3} \mathrm{Si}_{4} \mathrm{O}_{10}(\mathrm{OH})_{2}\right]$ as model system. J Chem Phys 139:204101

Wilkins RWT, Ito J (1967) Infrared spectra of some synthetic talcs. Am Mineral 52:1649502 1661

Wojdyr M (2010) Fityk: a general-purpose peak fitting program. J Appl Crystallogr 43:1126504 1128 
506 Table 1: Starting materials used for the preparation of talc precursors.

\begin{tabular}{lccrcc}
\hline Sample & $\begin{array}{c}\text { sodium metasilicate } \\
\text { pentahydrate }\end{array}$ & $\begin{array}{c}\text { magnesium acetate } \\
\text { tetrahydrate }\end{array}$ & $\begin{array}{c}\text { nickel } \\
\text { tetrahydrate }\end{array}$ & $\begin{array}{c}\text { acetate } \\
\text { acid }\end{array}$ & $\begin{array}{c}\text { sodium acetate } \\
\text { trihydrate }\end{array}$ \\
\hline Ni0 & $0.10 \mathrm{~mol}$ & $0.075 \mathrm{~mol}$ & $0.000 \mathrm{~mol}$ & $50.0 \mathrm{ml}$ & $50.0 \mathrm{~g}$ \\
$\mathrm{Ni} 25$ & $0.10 \mathrm{~mol}$ & $0.056 \mathrm{~mol}$ & $0.019 \mathrm{~mol}$ & $50.0 \mathrm{ml}$ & $50.0 \mathrm{~g}$ \\
Ni50 & $0.10 \mathrm{~mol}$ & $0.038 \mathrm{~mol}$ & $0.038 \mathrm{~mol}$ & $50.0 \mathrm{ml}$ & $50.0 \mathrm{~g}$ \\
Ni75 & $0.10 \mathrm{~mol}$ & $0.019 \mathrm{~mol}$ & $0.056 \mathrm{~mol}$ & $50.0 \mathrm{ml}$ & $50.0 \mathrm{~g}$ \\
Ni100 & $0.10 \mathrm{~mol}$ & $0.000 \mathrm{~mol}$ & $0.075 \mathrm{~mol}$ & $50.0 \mathrm{ml}$ & $50.0 \mathrm{~g}$ \\
\hline
\end{tabular}

511 Table 2: Calculated (this study) and experimental (Perdikatsis and Burzlaff 1981) cell

512 parameters and mean bond lengths of Mg-talc.

\begin{tabular}{lcc}
\hline & Calc. & Exp. \\
\hline$a(\AA)$ & 5.349 & 5.290 \\
$b(\AA)$ & 9.268 & 9.173 \\
$c(\AA)$ & 10.116 & 9.460 \\
$\alpha\left(^{\circ}\right)$ & 90.35 & 90.46 \\
$\beta\left(^{\circ}\right)$ & 98.28 & 98.68 \\
$\gamma\left(^{\circ}\right)$ & 90.01 & 90.09 \\
$\mathrm{Si}-\mathrm{O}(\AA)$ & 1.642 & 1.623 \\
$\mathrm{Mg}-\mathrm{O}(\AA)$ & 2.090 & 2.071 \\
$\mathrm{O}-\mathrm{H}(\AA)$ & 0.977 & - \\
\hline
\end{tabular}

513

514

515

516

517

518

519

520

521 
522 Table 3: Infrared-active $\mathrm{OH}$ stretching modes of $\mathrm{Mg}$-Ni talc samples: wavenumber $\left(W\right.$ in $\mathrm{cm}^{-}$

$\left.523^{1}\right)$ and relative integrated absorbance $(A)$ for the fundamental $(v \mathrm{OH})$ and first overtone bands

$524(2 \vee \mathrm{OH})$, anharmonicity constant calculated as follow $X=W_{2 v_{O H}} / 2-W_{\nu O H}$ (Bourdéron and

525 Sandorfy 1973). Data derived from the spectra decomposition shown in supplementary

526 information (Figs S2 and S3).

\begin{tabular}{|c|c|c|c|c|c|}
\hline Sample & $W_{\nu O H}$ & $A_{\nu O H}$ & $W_{2 \mathrm{vOH}}$ & $A_{2 \mathrm{vOH}}$ & $X$ \\
\hline $\mathrm{NiO}$ & 3677 & 1.00 & 7184 & 1.00 & -85 \\
\hline \multirow[t]{4}{*}{$\mathrm{Ni} 25$} & 3676 & 0.52 & 7184 & 0.43 & -84 \\
\hline & 3662 & 0.33 & 7154 & 0.35 & -85 \\
\hline & 3646 & 0.15 & 7119 & 0.19 & -86.5 \\
\hline & - & - & 7077 & 0.03 & - \\
\hline \multirow[t]{4}{*}{ Ni50 } & 3676 & 0.17 & 7185 & 0.18 & -83.5 \\
\hline & 3662 & 0.41 & 7156 & 0.34 & -84 \\
\hline & 3646 & 0.33 & 7121 & 0.34 & -85.5 \\
\hline & 3625 & 0.10 & 7078 & 0.14 & -86 \\
\hline \multirow[t]{4}{*}{ Ni75 } & 3676 & 0.03 & 7183 & 0.05 & -84.5 \\
\hline & 3662 & 0.25 & 7157 & 0.14 & -83.5 \\
\hline & 3647 & 0.43 & 7122 & 0.30 & -86 \\
\hline & 3625 & 0.28 & 7079 & 0.51 & -85.5 \\
\hline \multirow[t]{2}{*}{ Ni100 } & 3646 & 0.20 & 7123 & 0.17 & -84.5 \\
\hline & 3627 & 0.80 & 7080 & 0.83 & -87 \\
\hline
\end{tabular}

527

528

529

530

531

532

533

534

535

536 
538 Table 4: Theoretical infrared-active $\mathrm{OH}$ stretching modes of talc models: wavenumber ( $W$ in

$539 \mathrm{~cm}^{-1}$ ), normalized displacement (a.u.) of each of the four $\mathrm{H}$ atoms of the simulation cell

540 defined by their cationic environment, integrated molar absorption coefficient $\left(K_{\text {int }}\right.$ in $\mathrm{Lmol}^{-}$

$\left.541{ }^{1} \mathrm{~cm}^{-2}\right)$ and contribution of each mode to the total absorbance (\%).

\begin{tabular}{|c|c|c|c|c|c|c|}
\hline Model & $W$ & \multicolumn{4}{|c|}{ Norm. displ. and neighbor cations } & $K_{\text {int }}$ \\
\hline \multirow[b]{2}{*}{$\mathrm{Ni} 0$} & \multirow[b]{2}{*}{3848} & $3 \mathrm{Mg}$ & $3 \mathrm{Mg}$ & $3 \mathrm{Mg}$ & $3 \mathrm{Mg}$ & 8117 \\
\hline & & 0.49 & 0.49 & 0.48 & 0.48 & $100 \%$ \\
\hline \multirow{3}{*}{ Ni17 } & & $3 \mathrm{Mg}$ & $3 \mathrm{Mg}$ & $2 \mathrm{Mg} 1 \mathrm{Ni}$ & $2 \mathrm{Mg} 1 \mathrm{Ni}$ & 8958 \\
\hline & 3849 & 0.69 & 0.69 & 0.03 & 0.03 & $49.7 \%$ \\
\hline & 3826 & 0.03 & 0.03 & 0.69 & 0.69 & $50.3 \%$ \\
\hline \multirow{5}{*}{ Ni50a } & & $3 \mathrm{Mg}$ & $2 \mathrm{Mg} 1 \mathrm{Ni}$ & $1 \mathrm{Mg} 2 \mathrm{Ni}$ & $3 \mathrm{Ni}$ & 9327 \\
\hline & 3851 & 0.97 & 0.02 & 0.01 & 0.01 & $22.4 \%$ \\
\hline & 3828 & 0.02 & 0.97 & 0.02 & 0.01 & $24.5 \%$ \\
\hline & 3799 & 0.01 & 0.02 & 0.97 & 0.01 & $26.3 \%$ \\
\hline & 3762 & 0.01 & 0.01 & 0.01 & 0.97 & $26.8 \%$ \\
\hline \multirow{3}{*}{$\mathrm{Ni} 50 \mathrm{~b}$} & & $2 \mathrm{Mg} 1 \mathrm{Ni}$ & $2 \mathrm{Mg} 1 \mathrm{Ni}$ & $1 \mathrm{Mg} 2 \mathrm{Ni}$ & $1 \mathrm{Mg} 2 \mathrm{Ni}$ & 9778 \\
\hline & 3827 & 0.81 & 0.53 & 0.01 & 0.01 & $47.5 \%$ \\
\hline & 3797 & 0.01 & 0.01 & 0.74 & 0.63 & $52.5 \%$ \\
\hline \multirow{3}{*}{ Ni83 } & & $1 \mathrm{Mg} 2 \mathrm{Ni}$ & $1 \mathrm{Mg} 2 \mathrm{Ni}$ & $3 \mathrm{Ni}$ & $3 \mathrm{Ni}$ & 9377 \\
\hline & 3800 & 0.69 & 0.69 & 0.01 & 0.01 & $52.6 \%$ \\
\hline & 3762 & 0.01 & 0.01 & 0.69 & 0.69 & $47.4 \%$ \\
\hline \multirow[b]{2}{*}{ Ni100 } & & $3 \mathrm{Ni}$ & $3 \mathrm{Ni}$ & $3 \mathrm{Ni}$ & $3 \mathrm{Ni}$ & 8868 \\
\hline & 3765 & 0.49 & 0.49 & 0.48 & 0.48 & $100 \%$ \\
\hline
\end{tabular}

543

544 Table 5: Ni proportions in theoretical models estimated from the relative integrated

545 absorbances and compared to the exact value.

\begin{tabular}{ccc}
\hline Model & mol \% Ni from $A$ & Exact mol \% Ni \\
\hline Ni17 & 16.77 & 16.67 \\
Ni50a & 52.50 & 50.00 \\
Ni50b & 50.83 & 50.00 \\
Ni83 & 82.47 & 83.33 \\
\hline
\end{tabular}


Table 6: Ni proportions in synthetic samples estimated from the relative integrated absorbances of the fundamental and first overtone OH bands.

\begin{tabular}{ccc}
\hline Sample & mol \% Ni from $v \mathrm{OH}$ & mol \% Ni from $2 \mathrm{vOH}$ \\
\hline Ni0 & 0 & 0 \\
Ni25 & 21 & 27 \\
Ni50 & 45 & 48 \\
Ni75 & 66 & 75 \\
Ni100 & 93 & 94 \\
\hline
\end{tabular}

549

550

Table 7: Relative integrated absorbances for the fundamental $(\mathrm{vOH})$ and first overtone $(2 \mathrm{vOH}) \mathrm{OH}$ bands, calculated assuming a random distribution of octahedral cations (rand). In that case, we used the sample composition derived from infrared spectroscopy and the probabilities of occurrence of each $\mathrm{OH}$ band that are specified in the Table. Results are compared to the ones obtained by spectral decomposition (dec).

\begin{tabular}{|c|c|c|c|c|c|c|c|c|c|c|c|c|c|c|c|c|c|}
\hline \multirow[t]{2}{*}{$\mathrm{OH}$ group } & \multirow[t]{2}{*}{ Probability } & \multicolumn{2}{|c|}{$\mathrm{Ni} 25 \mathrm{vOH}$} & \multicolumn{2}{|c|}{$\mathrm{Ni25} 2 v \mathrm{OH}$} & \multicolumn{2}{|c|}{$\mathrm{Ni} 50 \vee \mathrm{OH}$} & \multicolumn{2}{|c|}{$\mathrm{Ni50} 2 v \mathrm{OH}$} & \multicolumn{2}{|c|}{$\mathrm{Ni} 75 \vee \mathrm{OH}$} & \multicolumn{2}{|c|}{$\mathrm{Ni} 752 v \mathrm{OH}$} & \multicolumn{2}{|c|}{$\mathrm{Ni100} v \mathrm{OH}$} & \multicolumn{2}{|c|}{$\mathrm{Ni100} 2 v \mathrm{OH}$} \\
\hline & & rand & $\mathrm{dec}$ & rand & $\mathrm{dec}$ & rand & $\mathrm{dec}$ & rand & $\mathrm{dec}$ & rand & dec & rand & dec & rand & $\mathrm{dec}$ & rand & dec \\
\hline $\mathrm{Mg}_{3} \mathrm{OH}$ & {$[\mathrm{Mg}]^{3}$} & 0.49 & 0.52 & 0.39 & 0.43 & 0.17 & 0.17 & 0.14 & 0.18 & 0.04 & 0.03 & 0.01 & 0.05 & 0.00 & 0.00 & 0.00 & 0.00 \\
\hline $\mathrm{Mg}_{2} \mathrm{NiOH}$ & $3[\mathrm{Mg}]^{2}[\mathrm{Ni}]$ & 0.39 & 0.33 & 0.43 & 0.35 & 0.41 & 0.41 & 0.39 & 0.34 & 0.23 & 0.25 & 0.14 & 0.14 & 0.01 & 0.00 & 0.01 & 0.00 \\
\hline $\mathrm{MgNi}_{2} \mathrm{OH}$ & $3[\mathrm{Mg}][\mathrm{Ni}]^{2}$ & 0.10 & 0.15 & 0.16 & 0.19 & 0.33 & 0.33 & 0.36 & 0.34 & 0.44 & 0.43 & 0.42 & 0.30 & 0.18 & 0.20 & 0.15 & 0.17 \\
\hline $\mathrm{Ni}_{3} \mathrm{OH}$ & {$[\mathrm{Ni}]^{3}$} & 0.01 & 0.00 & 0.02 & 0.03 & 0.09 & 0.10 & 0.11 & 0.14 & 0.29 & 0.28 & 0.43 & 0.51 & 0.81 & 0.80 & 0.84 & 0.83 \\
\hline
\end{tabular}




\section{Figure captions}

557 Figure 1: DFT optimized cell parameters of talc as a function of the Ni molar concentration. 558 Angles $\left(\alpha=90.35^{\circ}, \beta=98.28^{\circ}, \gamma=90.01^{\circ}\right)$ remain nearly constant over the Mg-Ni series.

560 Figure 2: Experimental (top) and theoretical mid-IR absorption spectra of Mg-talc (sample 561 and model Ni0) and Ni-talc (sample and model Ni100). Spectra have been computed for three 562 particle shapes: a plate perpendicular to the $\mathrm{c}^{*}$ axis, a sphere and an intermediate shape. The 563 trace of the imaginary part of the dielectric tensor computed for an infinite crystal (bottom) 564 serves as reference and indicates the frequency of normal modes in absence of the 565 depolarization field occurring in small particles.

567 Figure 3: Experimental IR spectra of $\mathrm{Mg}-\mathrm{Ni}$ synthetic talcs (in the regions of fundamental modes and first overtones of $\mathrm{OH}$ stretching vibrations) compared to theoretical spectra of fundamental modes. Vertical dashed lines are guides for the eye.

Figure 4: Scanning electron microscope images taken at the same scale of a natural talc (A)

572 and a talc synthesized using the present protocol (B) (images from F. Martin's library). C.

573 Schematic representation of a talc particle (left) and the same particle split in four (right), 574 highlighting that the basal surface remains constant in both cases while lateral surfaces are 575 doubled. This explains why the hydrophilic character of talc increases when the size of talc 576 particles decreases.

578 Figure 5: Structural models of the (100) and (010) surfaces of Mg-talc (left) and Ni-talc 579 (right), with the corresponding theoretical IR spectra of $\mathrm{OH}$ and $\mathrm{H}_{2} \mathrm{O}$ groups. Experimental IR 580 spectra in the $4000-2700 \mathrm{~cm}^{-1}$ range are shown for comparison (top). 
582 Figure 6: Comparison of relative integrated absorbances calculated assuming a random 583 distribution of octahedral cations and obtained by spectral decomposition. Solid and open 584 symbols correspond to fundamental and first overtone $\mathrm{OH}$ bands, respectively.

585

586 
Figure 1:

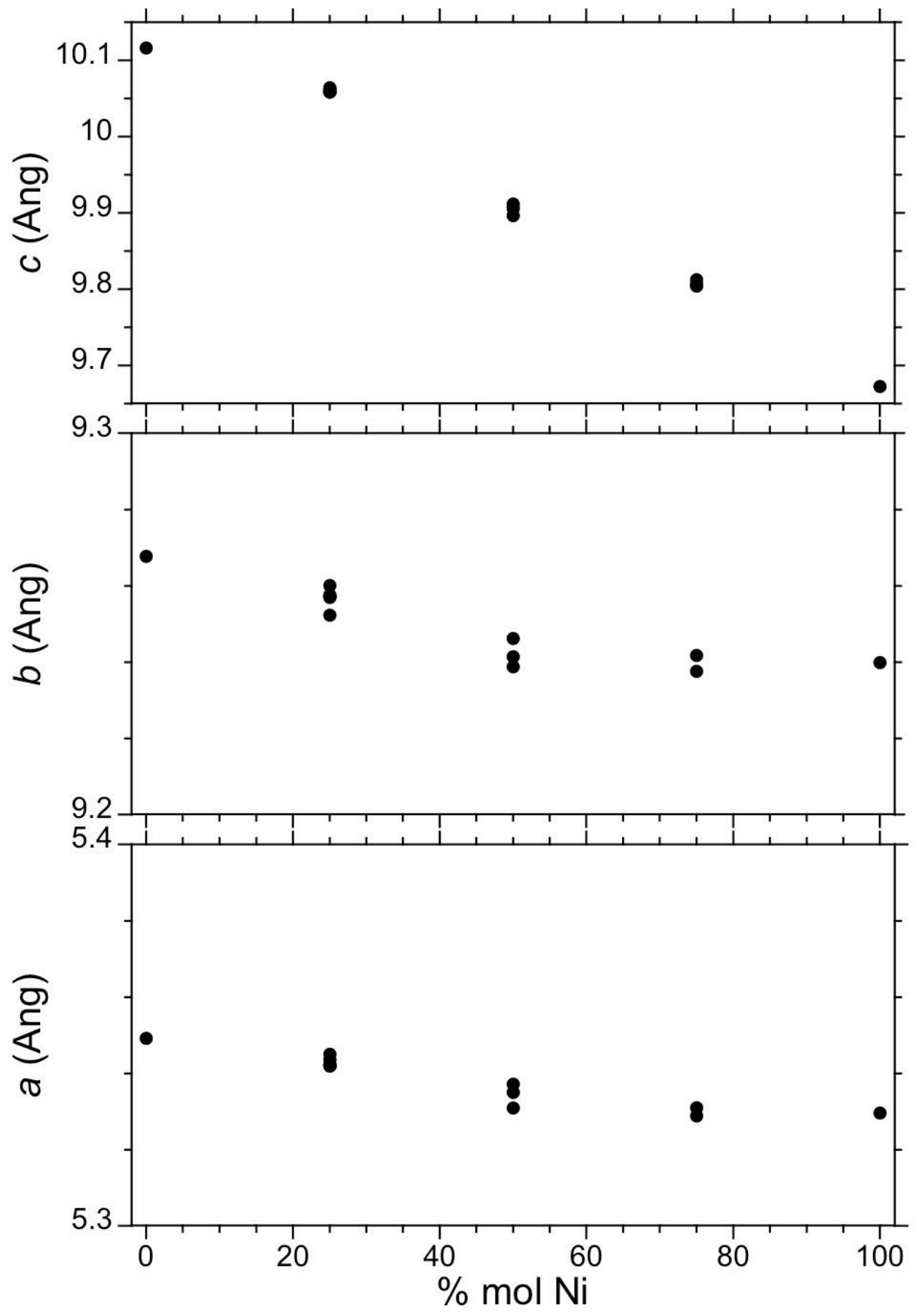


Figure 2:
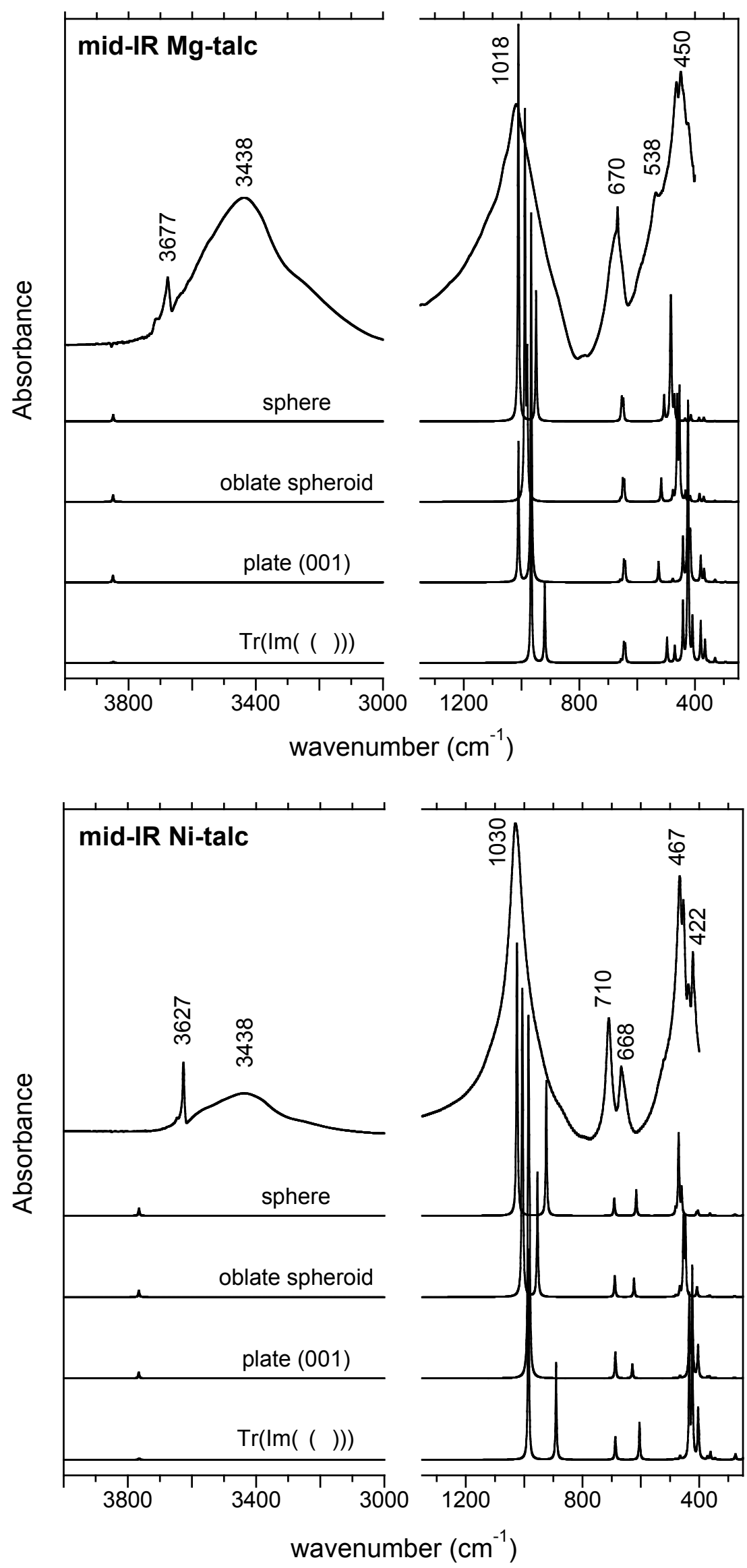
Figure 3:

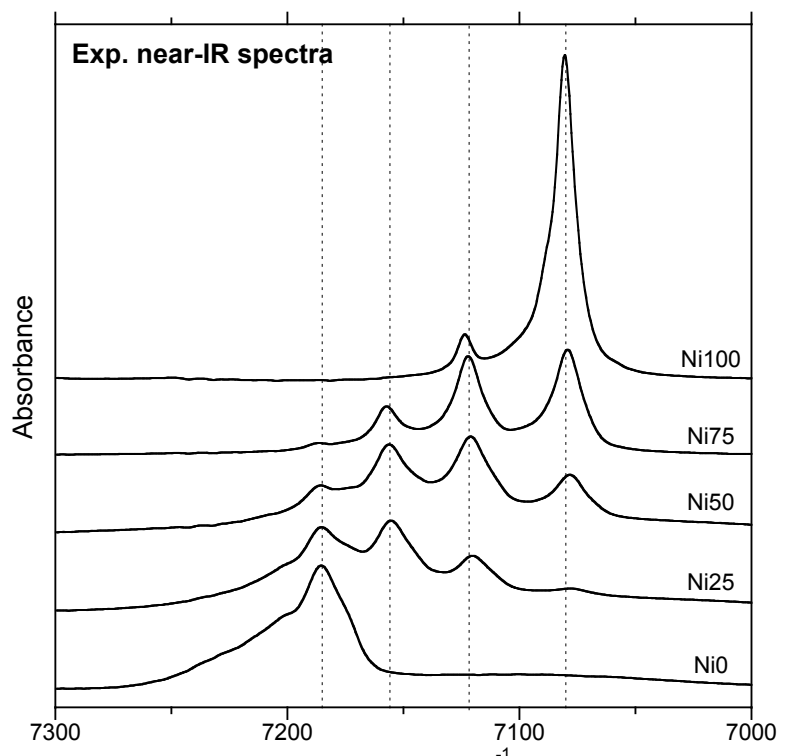

595 wavenumber $\left(\mathrm{cm}^{-1}\right)$

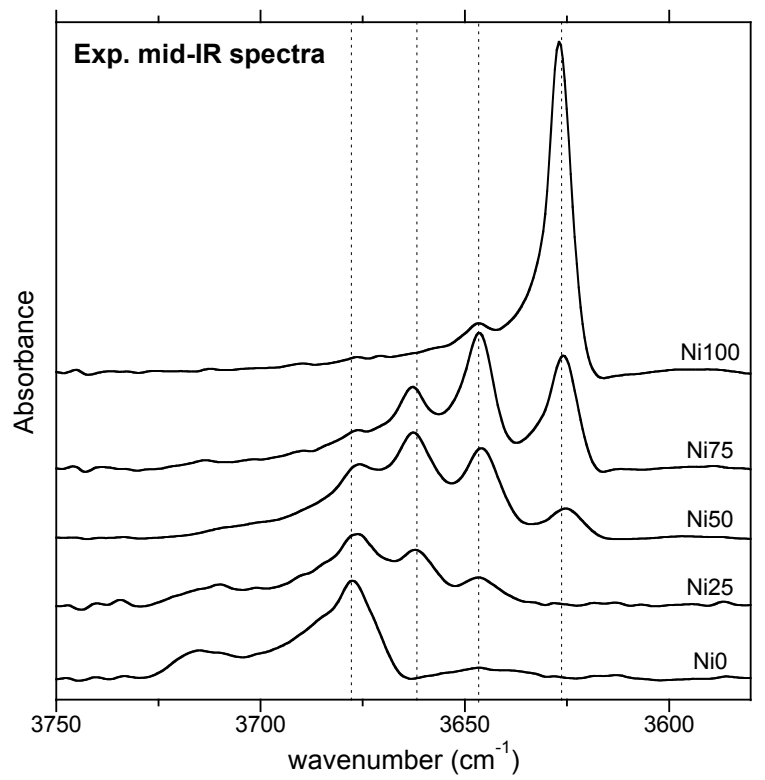

596

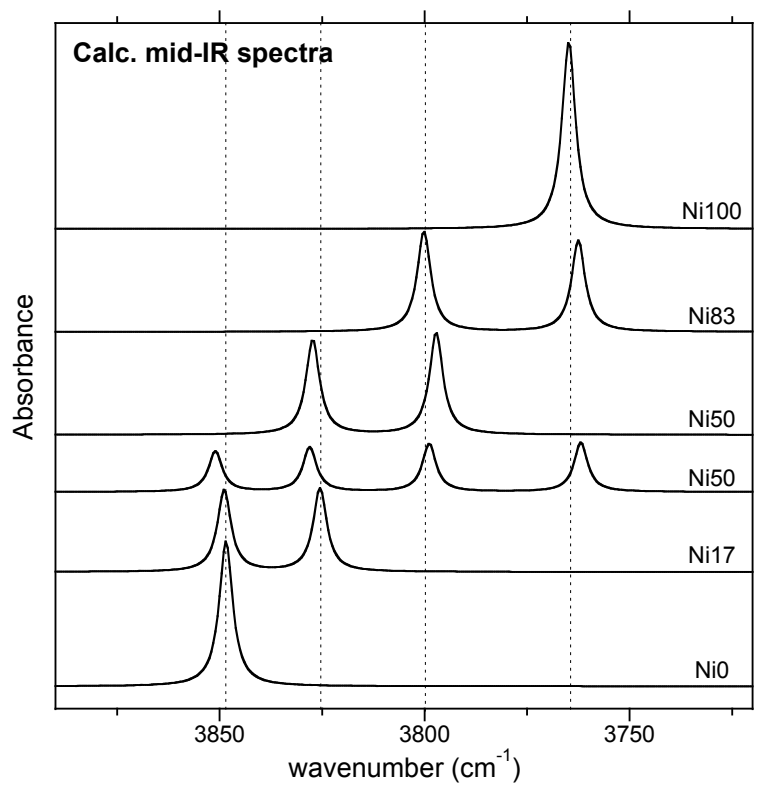


598 Figure 4:

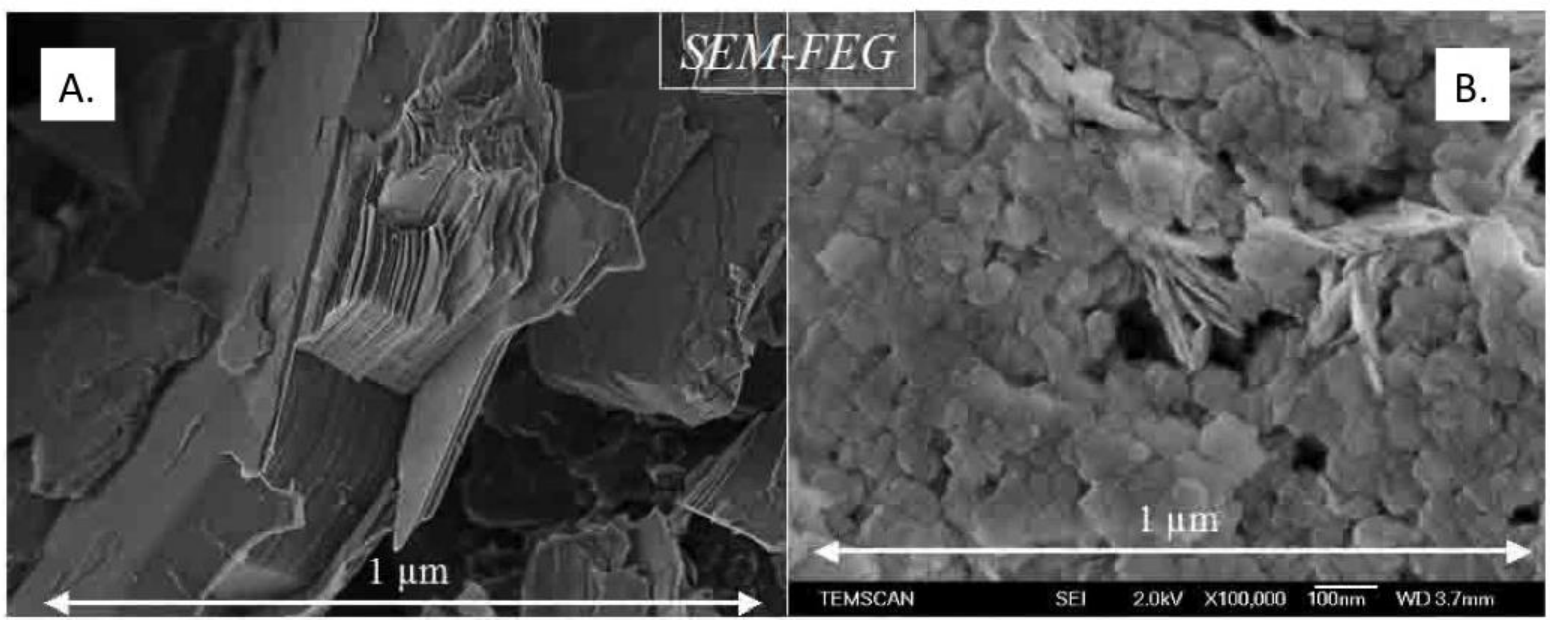

C.

Basal surface

(hydrophobic)
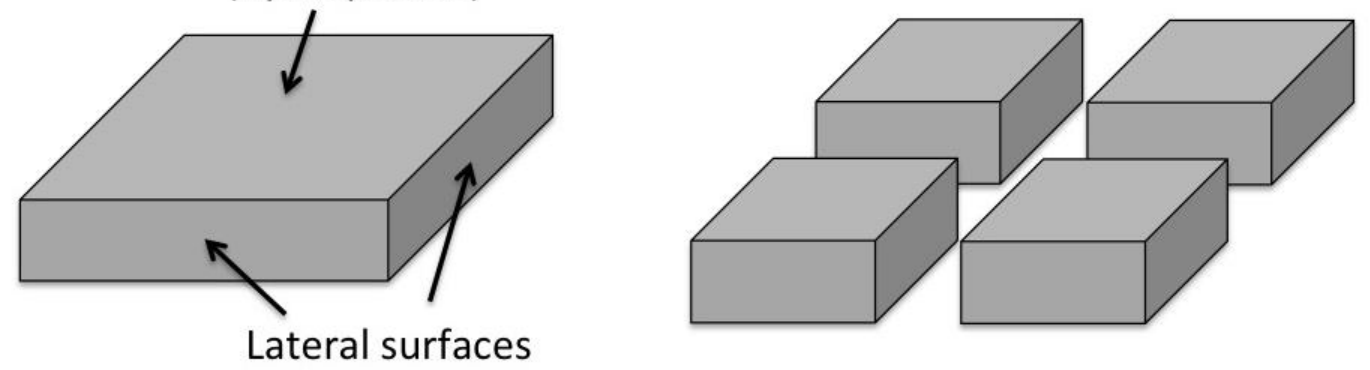

599

(hydrophilic)

600

601

602

603

604

605

606

607

608

609

610 
Figure 5:
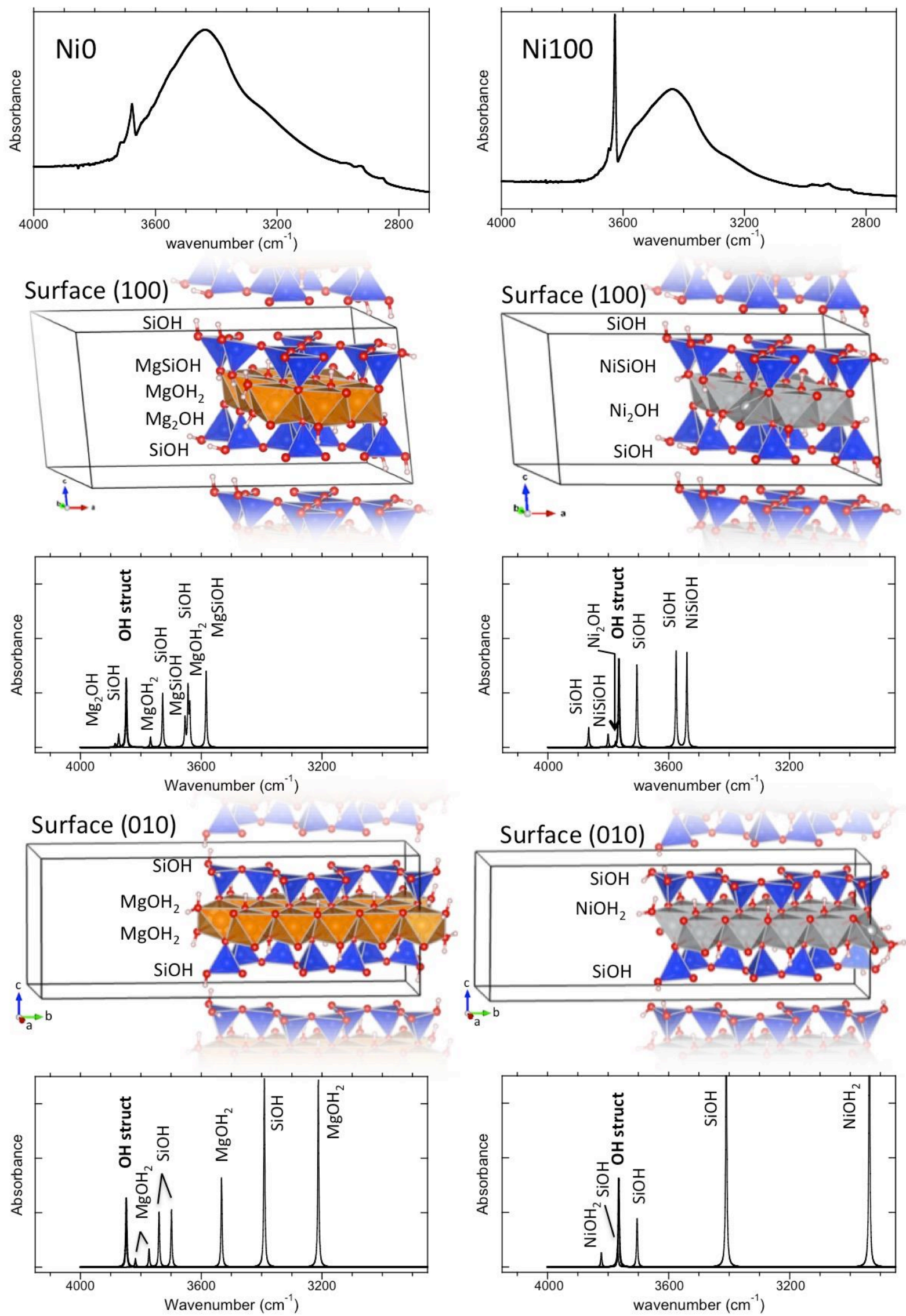
613 Figure 6:

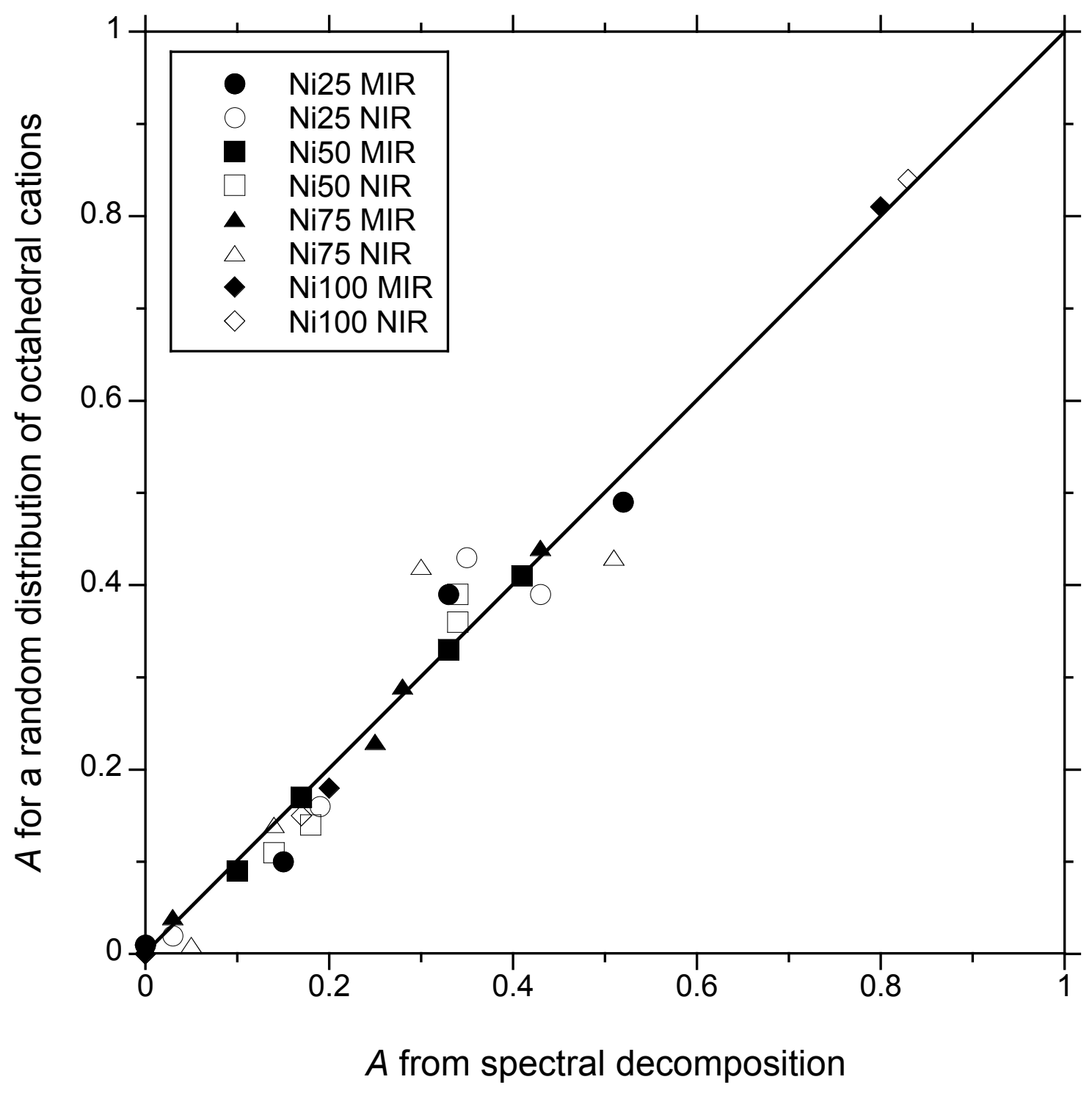

614

615 
Electronic Supplementary Material

Click here to access/download

Electronic Supplementary Material article_Ni_talc_SI.pdf 